\title{
4-Phenylbutyrate protects rat skin flaps against ischemia-reperfusion injury and apoptosis by inhibiting endoplasmic reticulum stress
}

\author{
ZHEN-SHUANG YUE，LIN-RU ZENG，REN-FU QUAN，YANG-HUA TANG，WEN-JIE ZHENG, \\ GANG QU, CAN-DA XU, FANG-BING ZHU and ZHONG-MING HUANG
}

Department of Orthopedics, Xiaoshan Traditional Chinese Medical Hospital, Hangzhou, Zhejiang 311201, P.R. China

Received January 26, 2015; Accepted November 18, 2015

DOI: $10.3892 / \mathrm{mmr} .2015 .4636$

\begin{abstract}
PBA) is a low molecular weight fatty acid, which has been demonstrated to regulate endoplasmic reticulum (ER) stress. ER stress-induced cell apoptosis has an important role in skin flap ischemia; however, a pharmacological approach for treating ischemia-induced ER dysfunction has yet to be reported. In the present study, the effects of 4-PBA-induced ER stress inhibition on ischemia-reperfusion injury were investigated in the skin flap of rats, and transcriptional regulation was examined. 4-PBA attenuated ischemia-reperfusion injury and inhibited cell apoptosis in the skin flap. Furthermore, 4-PBA reversed the increased expression levels of two ER stress markers: CCAAT/enhancer-binding protein-homologous protein and glucose-regulated protein 78 . These results suggested that 4-PBA was able to protect rat skin flaps against ischemia-reperfusion injury and apoptosis by inhibiting ER stress marker expression and ER stress-mediated apoptosis. The beneficial effects of 4-PBA may prove useful in the treatment of skin flap ischemia-reperfusion injury.
\end{abstract}

\section{Introduction}

A skin flap is a common autograft procedure, which has been widely used in surgical practice. Skin flaps are often used to repair wounds, as well as in the field of plastic and reconstructive surgery (1). However, the clinical application of skin flaps for tissue repair and organ reconstruction is often accompanied by ischemia-reperfusion injury. Ischemia results in tissue reperfusion injury with the restoration of blood flow, which may lead to partial or complete skin flap necrosis,

Correspondence to: Dr Ren-Fu Quan, Department of Orthopedics, Xiaoshan Traditional Chinese Medical Hospital, 156 Yucai Road, Hangzhou, Zhejiang 311201, P.R. China

E-mail: quanrenf@263.net

Key words: skin flap ischemia, endoplasmic reticulum stress, 4-phenylbutyrate, apoptosis and a decrease in the success rate of the surgical procedure. Therefore, reducing skin flap ischemia-reperfusion injury is of important clinical significance. Numerous compounds have been demonstrated to reduce ischemia-reperfusion injury; however, clinical trials have yet to be successful due to toxic side-effects (2). Therefore, the development of novel drugs and the identification of novel mechanisms for the treatment of skin flap ischemia are required.

Endoplasmic reticulum (ER) stress is defined as an accumulation of unfolded or misfolded proteins in the ER, a subcellular organelle predominantly involved in protein folding (3-6). The ER is also responsible for regulating protein synthesis, protein folding and trafficking, and intracellular calcium levels $(7,8)$. Accumulation of unfolded or misfolded proteins in the ER may result in initiation of the unfolded protein response (UPR) or ER stress. Activation of the UPR may increase the expression levels of CCAAT/enhancer-binding protein-homologous protein (CHOP) and glucose-regulated protein 78 (GRP78). CHOP, which is considered a marker of ER stress, is an apoptotic transcription factor that is induced in response to ER stress (9). In addition, GRP78 is an ER chaperone, which stably interacts with unfolded or misfolded proteins; therefore, upregulation of GRP78 expression is commonly considered a marker of ER stress $(3,10)$. It has previously been demonstrated that ER stress mediates cell apoptosis by generating endogenous reactive oxygen species or disturbing mitochondrial $\mathrm{Ca}^{2+}$ homeostasis, leading to the activation of caspase-3, which is a regulator of caspase-dependent apoptosis (11). Therefore, targeting the ER may provide a therapeutic approach for blocking the pathological progression induced by skin flap ischemia.

4-phenylbutyrate (4-PBA) has been demonstrated to contribute to the treatment of spinal muscular atrophy by altering gene expression patterns $(12,13)$. Furthermore, 4-PBA is able to inhibit disease progression and neuroinflammation in multiple sclerosis (14). Numerous studies have described the use of 4-PBA as a chemical chaperone that reverses the mislocalization and/or aggregation of proteins associated with human disease (15-17). In addition, 4-PBA reduces the levels of mutant or dislocated proteins retained in the ER under conditions associated with cystic fibrosis and liver injury (18). Despite the fact that skin flaps have been shown to cause ER 
dysfunction, it remains unclear whether 4-PBA is able to protect against ischemia-reperfusion-induced damage, and regulate the protein expression of ER stress markers.

The present study used in vivo experimental systems to examine the effects of ER stress, as well as the underlying molecular mechanisms, on ischemia-reperfusion in rat skin flaps. The effects of 4-PBA may provide a novel therapeutic strategy for the treatment of skin flap ischemia-reperfusion injury.

\section{Materials and methods}

Induction of ischemia-reperfusion and 4-PBA treatment. Care of the laboratory animals and animal experimentation were performed in accordance with animal ethics guidelines and approved protocols. All animal studies were approved by the Animal Ethics Committee of the Xiaoshan Traditional Chinese Medical Hospital (Hangzhou, China). A total of 75 healthy male Wistar rats (age, 6 weeks; weight, 300-350 g; Shanghai SLAC Laboratory Animal Co., Ltd., Shanghai, China) were randomly divided into three groups: The control group; the ischemia-reperfusion and 4-PBA administration group; and the ischemia-reperfusion and saline administration group, which served as a negative control (NC). Each group comprised 25 rats. The rats were maintained at room temperature, in a 12-h light/dark cycle with access to food and water ad libitum. Preparation of a skin flap was performed in all of the rats, as follows: The rats were anesthetized with 3\% sodium pentobarbital (40 mg/kg; Sigma-Aldrich, St. Louis, MO, USA) by intraperitoneal injection, their limbs were subsequently fixed, and the fur on their abdomens was sheared. The skin of the abdomen was sterilized with $75 \%$ alcohol. A right lower abdominal island skin flap $(6 \times 3 \mathrm{~cm})$ was created, according to the method described by Shimamatsu and Wanless (19). In the control group, no other treatments were performed. In the 4-PBA and NC groups, the femoral artery located at the proximal end of the superficial epigastric artery was occluded using a vascular clamp. An OPMI 1 FR pro surgical microscope (Carl Zeiss AG, Oberkochen, Germany) was used to confirm the femoral artery and superficial epigastric artery were completely occluded. The flap was then sutured and the vascular clamp was removed after $8 \mathrm{~h}$.

4-PBA was prepared by titrating equimolar amounts of 4-phenylbutyric acid (Wako Pure Chemicals Co., Ltd., Tokyo, Japan) and sodium hydroxide to $\mathrm{pH}$ 7.4. 4-PBA was administered intragastrically at a volume of $2 \mathrm{ml} / \mathrm{kg} 24 \mathrm{~h}$ and $30 \mathrm{~min}$ prior to the surgical procedure in the 4-PBA group. Saline was administered in the NC group. In the NC and 4-PBA groups, a $1 \times 0.5 \mathrm{~cm}$ skin flap tissue sample was removed at the time the skin flap was created $(0 \mathrm{~h})$, and 1, 6, 12 and $24 \mathrm{~h}$ following ischemia-reperfusion. In the control group, a $1 \mathrm{x} 0.5 \mathrm{~cm}$ skin flap tissue sample was removed at the time the skin flap was created $(0 \mathrm{~h})$, and $1,6,12$ and $24 \mathrm{~h}$ following the surgical procedure.

Histology. The skin flap samples of the rats were removed and fixed with $10 \%$ (v/v) neutral-buffered formalin. The tissue samples were then dehydrated and embedded in paraffin. For histological examination, $4 \mu \mathrm{m}$ sections of the fixed embedded tissue samples were cut using a Leica 2165 rotary microtome
(Leica Microsystem GmbH, Wetzlar, Germany). The sections were placed on glass slides, deparaffinized, and stained sequentially with hematoxylin and eosin (Richard-Allan Scientific Co., Kalamazoo, MI, USA). The stained tissue sections were analyzed using a light microscope (Axio Imager M1; Carl Zeiss AG) at x100 magnification.

Terminal deoxynucleotidyl transferase dUTP nick end labeling (TUNEL) staining. TUNEL staining was performed using the Roche In Situ Cell Death Detection kit for the detection of programmed cell death (Roche Applied Science, Pleasanton, CA, USA) (20). The tissue sections were then examined by microscopy (CX41RF; Olympus Corporation, Tokyo, Japan) and the number of TUNEL-positive cells was counted using National Institutes of Health (NIH) Image software version 1.61 (NIH, Bethesda, MA, USA).

Reverse transcription-quantitative polymerase chain reaction $(R T-q P C R)$. Total RNA was isolated from the rat skin flap tissue samples using TRIzol ${ }^{\circledR}$ reagent (Invitrogen; Thermo Fisher Scientific, Inc., Waltham, MA, USA), as previously described (21) and stored at $-80^{\circ} \mathrm{C}$. cDNA was reverse transcribed from RNA using a cDNA synthesis kit (Thermo Fisher Scientific, Inc.). The cDNA synthesis conditions were as follows: $37^{\circ} \mathrm{C}$ for $60 \mathrm{~min}$, followed by $85^{\circ} \mathrm{C}$ for $5 \mathrm{~min}$ and $4^{\circ} \mathrm{C}$ for $5 \mathrm{~min}$. A DyNAmo Flash SYBR ${ }^{\circledR}$ Green qPCR kit (Finnzymes Oy, Espoo, Finland) was used, according to the manufacturer's protocol, the thermal cycler used was an ABI 7500 (Applied Biosystems; Thermo Fisher Scientific, Inc.) in order to detect the mRNA expression levels of CHOP and GRP78. The gene expression was calculated using the $2^{-\Delta \Delta C q}$ method (22). The following primers were used: CHOP, forward 5'-GGAGAAGGAGCAGGAGAATG-3', reverse 5'-GAGACA GACAGGAGGTGATG-3'; GRP78, forward 5'-TAATCAGCC CACCGTAAC-3', reverse 5'-GTTTCCTGTCCCTTTGTC-3'; and glyceraldehyde 3-phosphate dehydrogenase (GAPDH), forward. 5'-GTCGGTGTGAACGGATTTG-3', and reverse 5'-TCCCATTCTCAGCCTTGAC-3' (Sangon Biotech Co., Ltd., Shanghai, China). Relative quantification of the signals was performed by normalizing the gene signals with those of GAPDH. The PCR cycling conditions were as follows: $95^{\circ} \mathrm{C}$ for $10 \mathrm{~min}$; followed by 40 cycles at $95^{\circ} \mathrm{C}$ for $15 \mathrm{sec}$ and $60^{\circ} \mathrm{C}$ for $45 \mathrm{sec}$; and a final extension step of $95^{\circ} \mathrm{C}$ for $15 \mathrm{sec}, 60^{\circ} \mathrm{C}$ for $1 \mathrm{~min}, 95^{\circ} \mathrm{C}$ for $15 \mathrm{sec}$ and $60^{\circ} \mathrm{C}$ for $15 \mathrm{sec}$.

Western blotting. The skin flaps were homogenized and total cell lysates were extracted using radioimmunoprecipitation assay buffer (JRDUN Biotechnology, Co., Ltd., Shanghai, China), containing $50 \mathrm{mmol} / \mathrm{l}$ Tris- $\mathrm{HCl}$ (pH 8.8), $150 \mathrm{mmol} / \mathrm{l}$ $\mathrm{NaCl}, 1 \%$ Triton $\mathrm{X}-100,0.1 \%$ SDS and $1 \%$ deoxycholic acid sodium. Total protein concentration in each tissue sample was measured using a Lowry protein assay kit (Bio-Rad Laboratories, Inc., Hercules, CA, USA). Equivalent quantities $(50 \mu \mathrm{g})$ of protein lysates were separated by 10 or $15 \%$ sodium dodecyl sulfate-polyacrylamide gel electrophoresis and transferred to nitrocellulose membranes (Sigma-Aldrich), followed by blocking in fat-free milk overnight at $4^{\circ} \mathrm{C}$. The membranes were incubated with primary antibodies for $2 \mathrm{~h}$ with gentle agitation at room temperature, or overnight at $4^{\circ} \mathrm{C}$, and then washed three times with Tris-buffered saline 
with Tween 20 (Amresco, LLC, Solon, OH, USA). The following primary antibodies were used and diluted as per the manufacturer's recommendations: Rabbit monoclonal anti-GRP78 (1:1,000; Abcam, Cambridge, MA, USA; cat. no. ab108613), mouse monoclonal anti-CHOP (1:1,000; Cell Signaling Technology, Inc., Danvers, MA, USA; cat. no. 2895) and rabbit monoclonal anti-GAPDH (1:1,500; Cell Signaling Technology Inc.; cat. no. 5174) for $2 \mathrm{~h}$ at $4^{\circ} \mathrm{C}$. The membranes were then incubated for $1 \mathrm{~h}$ at $37^{\circ} \mathrm{C}$ with either anti-mouse or anti-rabbit horseradish peroxidase-conjugated immunoglobulin G secondary antibodies (1:1,000; Dako North America, Inc., Carpinteria, CA, USA; cat. nos. A0208 and A0216). Chemiluminescence detection was conducted using Western Lightning Chemiluminescence Reagent Plus (PerkinElmer, Inc., Waltham, MA, USA) and signals were quantified by densitometry (Quantity One software, version 4.62; Bio-Rad Laboratories, Inc.).

Immunofluorescence staining for CHOP and GRP78. Paraffin-embedded skin flap tissue sections were deparaffinized and hydrated for histological assessment. For antigen retrieval, the tissues were put into the sodium citrate solution (JRDUN Biotechnology, Co., Ltd.) and heated using a microwave oven at $92-98^{\circ} \mathrm{C}$ for $10-30 \mathrm{~min}$. Following antigen retrieval, the tissue sections were permeabilized with $0.1 \%$ Triton X-100 in phosphate-buffered saline (PBS). Following blocking with $2 \%$ bovine serum albumin (Sigma-Aldrich, Shanghai, China) in PBS for $1 \mathrm{~h}$, the tissue sections were incubated with the anti-GRP78 and anti-CHOP antibodies, prior to incubation with the corresponding fluorescein isothiocyanate-conjugated secondary antibody. The nuclei were then stained with 4',6-diamidino-2-phenylindole. The fluorescence signal was measured by CX41RF microscope at magnification $\mathrm{x} 200$.

Statistical analysis. The data are presented as the mean \pm standard deviation. A paired, two-tailed Student's t-test was used to analyze the significance of statistical differences between the groups. Statistical analyses were performed using GraphPad Prism software, version 5 (GraphPad Software, Inc., La Jolla, CA, USA) and $\mathrm{P}<0.05$ was considered to indicate a statistically significant difference.

\section{Results}

4-PBA attenuates ischemia-reperfusion injury in the skin flap of the rats. Histological analyses detected significant swelling and increased numbers of inflammatory cells in the tissue space of the NC group at $6 \mathrm{~h}$, and the injury increased in severity $24 \mathrm{~h}$ following ischemia-reperfusion. Conversely, the morphological structure of the control group was normal, and no such changes were observed. The presence of abnormal cells was markedly increased in the NC group, as compared with in the 4-PBA group, in which damaged and inflammatory cells, and swelling in the tissue sections were rarely observed (Fig. 1).

4-PBA inhibits cell apoptosis in the skin flap. To determine whether 4-PBA was associated with antiapoptotic activity, apoptosis was evaluated using a TUNEL assay. The results demonstrated anincrease in the number of TUNEL-positivecells to 28.6 and $48.4 \%, 6$ and $24 \mathrm{~h}$ following ischemia-reperfusion injury, respectively. Treatment with 4-PBA significantly decreased the number of TUNEL-positive cells in the skin flap by $\sim 19.4$ and $26.1 \%$, as compared with administration of saline, at 6 and $24 \mathrm{~h}$ following ischemia-reperfusion (Fig. 2). Furthermore, the number of TUNEL-positive cells in the NC group increased in a time-dependent manner, with a statistically significant increase $6 \mathrm{~h}$ following ischemia-reperfusion.

\section{4-PBA suppresses the mRNA expression of CHOP and GRP78} in the skin flap. To evaluate whether ER stress was involved in ischemia-reperfusion injury in the skin flap, the mRNA expression levels of CHOP and GRP78 were quantified in the skin flap tissue samples of the rats. The mRNA expression levels of CHOP were increased by $\sim 61.1,88.9$ and $161 \%$ at 6 , 12 , and $24 \mathrm{~h}$ following ischemia-reperfusion, respectively, as compared with the control group at 14, 20 and $32 \mathrm{~h}$ following skin flap creation (Fig. 3A). The mRNA expression levels of GRP78 were increased by $\sim 34.0,64.7$ and $126 \%$ at 6,12 , and $24 \mathrm{~h}$ following ischemia-reperfusion, respectively, as compared with the control group at 6,12 and $24 \mathrm{~h}$ following skin flap creation (Fig. 3B).

The increases in CHOP and GRP78 mRNA expression levels were significantly reduced following administration of 4-PBA from 6-24 h ( 16.8, 17.4 and $32.9 \%$ reduction in CHOP expression levels, and $\sim 14.2,19.2$ and $29.9 \%$ reduction in GRP78 expression levels), as compared with the NC group (Fig. 3).

4-PBA inhibits the upregulation of CHOP and GRP78 protein expression in skin flap tissue samples. The protein expression levels of CHOP and GRP78 were examined by western blot analysis. The results demonstrated that the protein expression levels of CHOP and GRP78 were similar to the mRNA expression levels, and were significantly increased $24 \mathrm{~h}$ following ischemia-reperfusion (Fig. 4A). Pretreatment with 4-PBA significantly inhibited the increases in protein expression levels of CHOP and GRP78 in the skin flap tissue samples at 6 and $24 \mathrm{~h}$ following ischemia-reperfusion.

To further investigate the hypothesis that CHOP and GRP78 expression levels were increased in the rat skin flap tissue samples following ischemia-reperfusion injury, these proteins were visualized by immunofluorescence staining (Fig. 4B). Fluorescence microscopy revealed that the expression of CHOP and GRP78 were markedly increased at $24 \mathrm{~h}$ following ischemia-reperfusion, as compared with the control group. However, following pretreatment with 4-PBA, the increases in CHOP and GRP78 protein expression were significantly inhibited at $24 \mathrm{~h}$ in the skin flap tissue samples following ischemia-reperfusion.

\section{Discussion}

To the best of our knowledge, the results of the present study demonstrated for the first time that the intragastric administration of 4-PBA at therapeutic doses protected rat skin flaps against ischemia-reperfusion injury. The protective effects of 4-PBA were further demonstrated by an inhibition of ER stress, and a decrease in the number of apoptotic cells. 

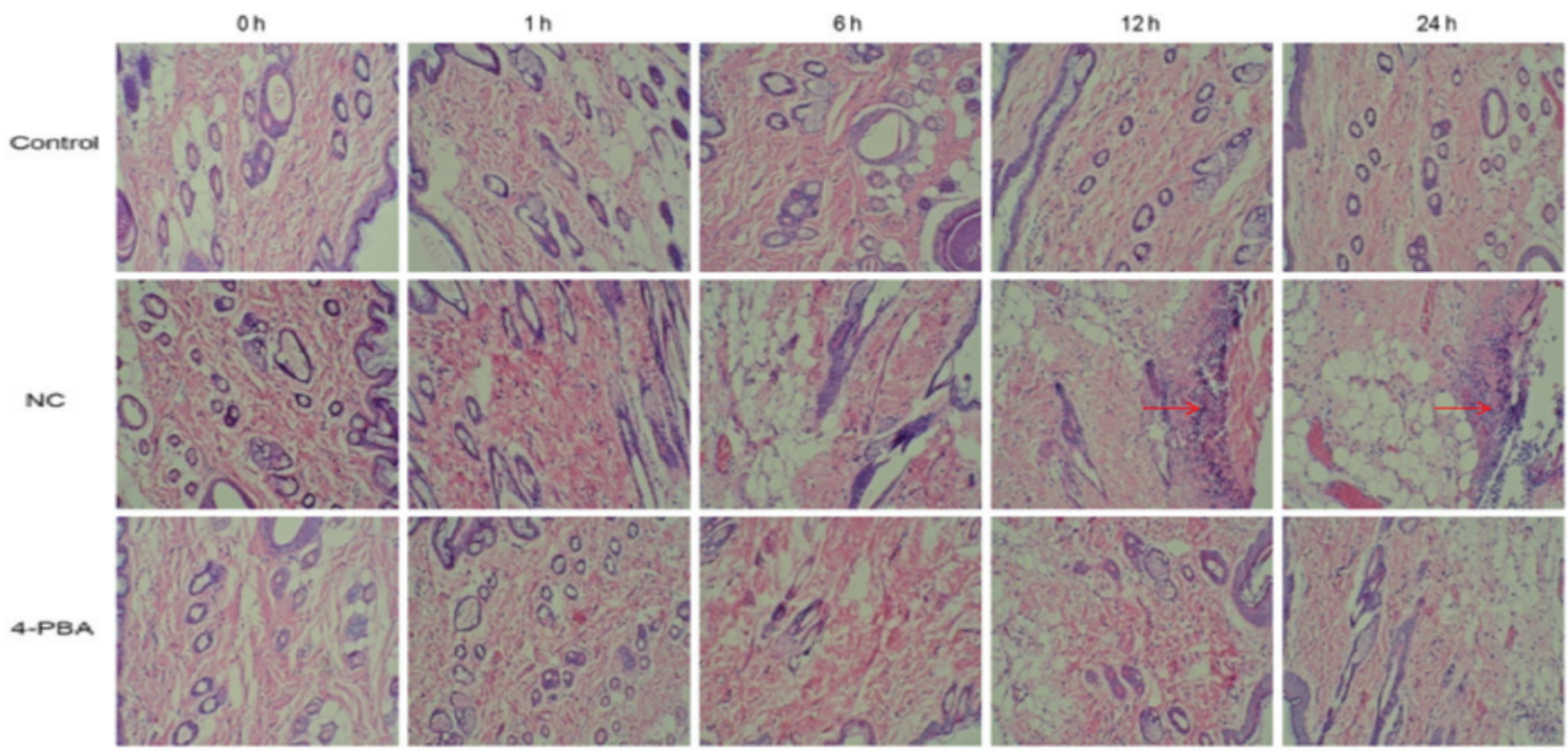

Figure 1. 4-PBA attenuates ischemia-reperfusion injury in the skin flap of rats. Skin flap tissue sections from rats undergoing ischemia-reperfusion were stained with hematoxylin and eosin (magnification, x100). Significant swelling and increased numbers of inflammatory cells were detected in the tissue space of the NC group rats; however, these characteristics were absent from the control group, and attenuated in the 4-PBA group rats. Tissue sections were observed $0,1,6,12$, and $24 \mathrm{~h}$ following ischemia-reperfusion. NC, negative control; 4-PBA, 4-phenylbutyrate.
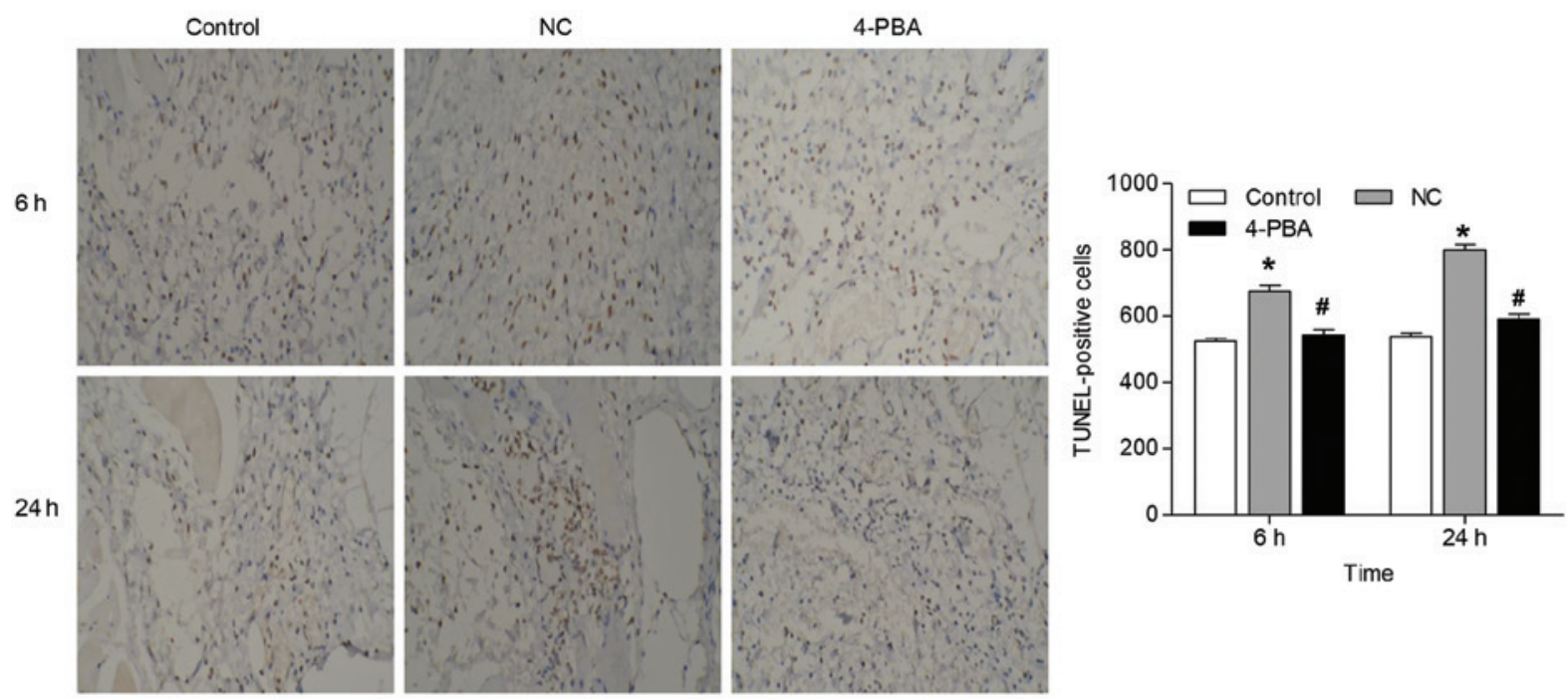

Figure2.4-PBAinhibitscellapoptosisintheskinflapofrats.Pretreatmentwith4-PBAdecreasedthenumberofTUNEL-positivecellsinducedbyischemia-reperfusion injury. To estimate the number of TUNEL-positive cells, the TUNEL-positive area was determined using National Institutes of Health Image software. The error bars represent the mean \pm standard deviation from five rats/group. ${ }^{*} \mathrm{P}<0.05$, vs. the control group; ${ }^{*} \mathrm{P}<0.05$, vs. the rats treated with saline (NC). NC, negative control; 4-PBA, 4-phenylbutyrate; TUNEL, terminal deoxynucleotidyl transferase dUTP nick end labeling.

Notably, administration of 4-PBA was effective not only prior to but also following ischemia-reperfusion injury.

Ischemia-reperfusion injury is a severe limitation in the survival of tissues involved in reconstructive microsurgery, and skeletal muscles and skin flaps are particularly susceptible (23-26). 4-PBA is a potent ER stress inhibitor and numerous studies have reported the effect of 4-PBA on ischemia-reperfusion injury $(27,28)$. Consistent with these observations, the results of the present study demonstrated that pretreatment with 4-PBA markedly attenuated ischemia-reperfusion injury in the skin flap of rats, and damaged and inflammatory cells and tissue swelling were rarely observed. In addition, the data demonstrated that 4-PBA attenuated ER stress-mediated cell apoptosis in the rat skin flaps following ischemia-reperfusion injury. Therefore, targeting the ER-mediated apoptotic signaling pathway may be an effective strategy for the treatment of cellular injury.

ER stress is involved in the pathogenesis of various cardiovascular diseases, and promotes disease progression (29). CHOP is a downstream component of ER stress 

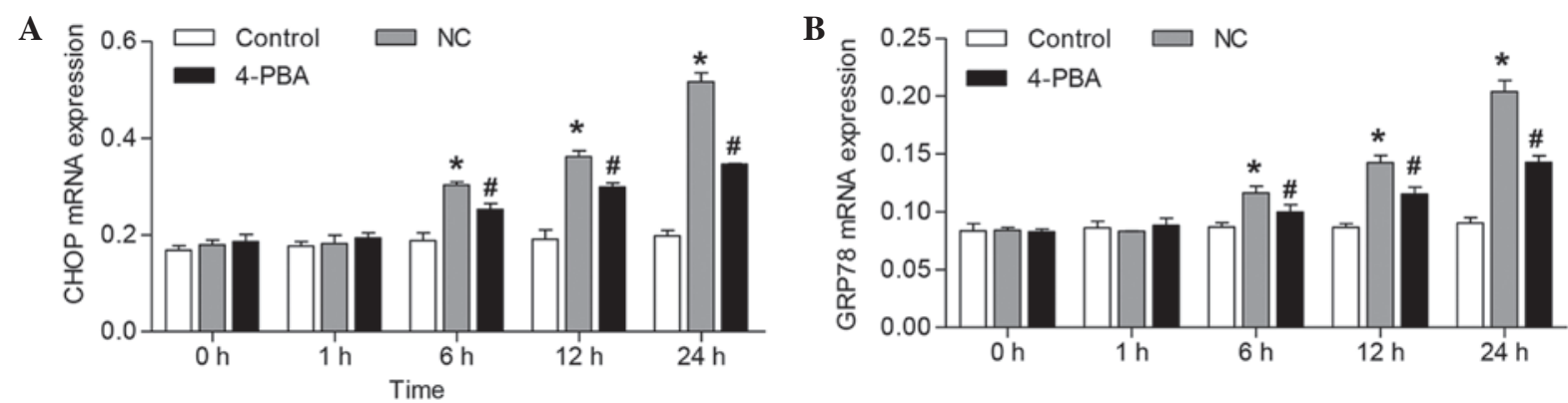

Figure 3. Effects of 4-PBA on the mRNA expression levels of CHOP and GRP78 in the skin flap tissue samples of rats following ischemia-reperfusion. Reverse transcription-quantitative polymerase chain reaction analysis of (A) CHOP and (B) GRP78 in the skin flap tissue samples of the rats. Expression levels were detected $0,1,6,12$, and $24 \mathrm{~h}$ following ischemia-reperfusion. The error bars represent the mean \pm standard deviation from five rats per group ${ }^{*} \mathrm{P}<0.05$, vs. the control group; ${ }^{\text {P }}<0.05$, vs. the rats treated with saline (NC). NC, negative control; 4-PBA, 4-phenylbutyrate; CHOP, CCAAT/enhancer-binding protein-homologous protein; GRP78, glucose-regulated protein 78.

A
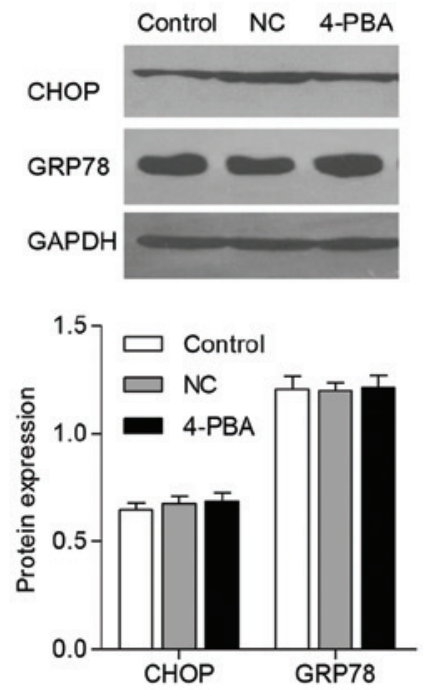

B
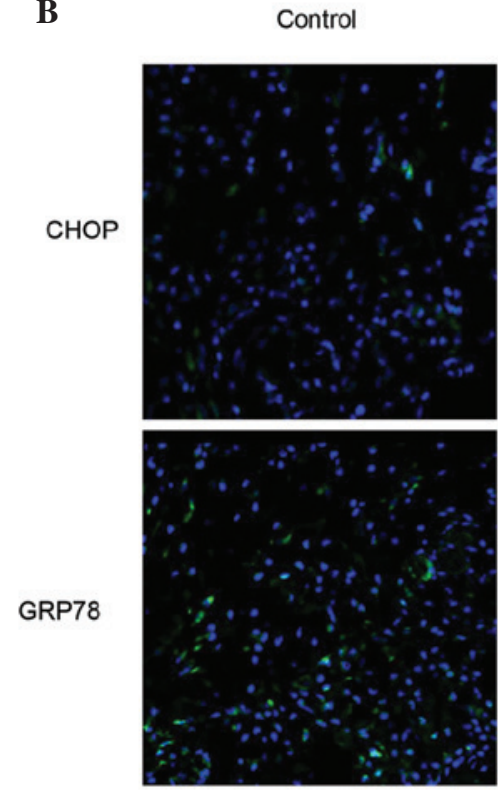

$6 \mathrm{~h}$
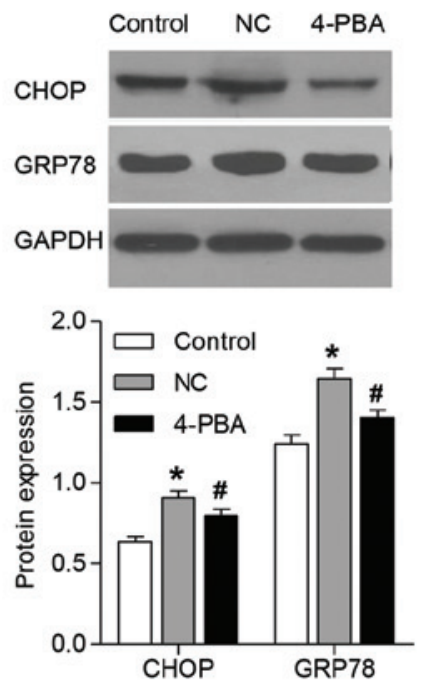

NC
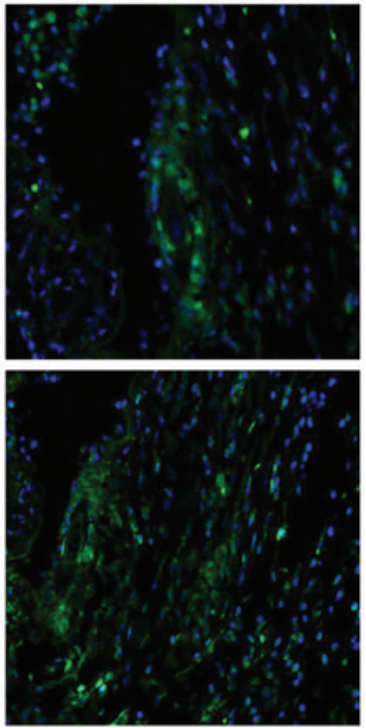

$24 \mathrm{~h}$
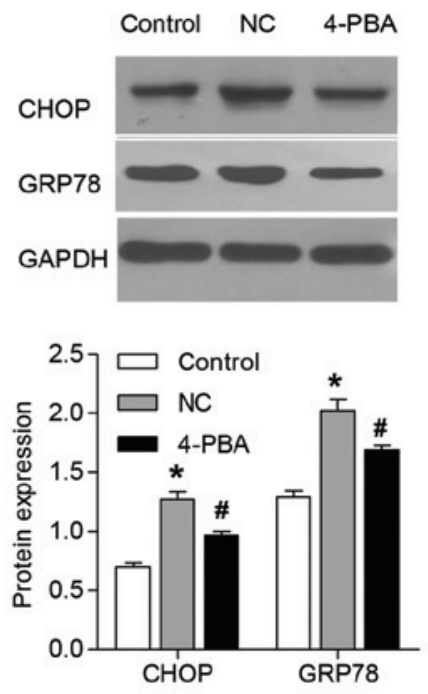

4-PBA
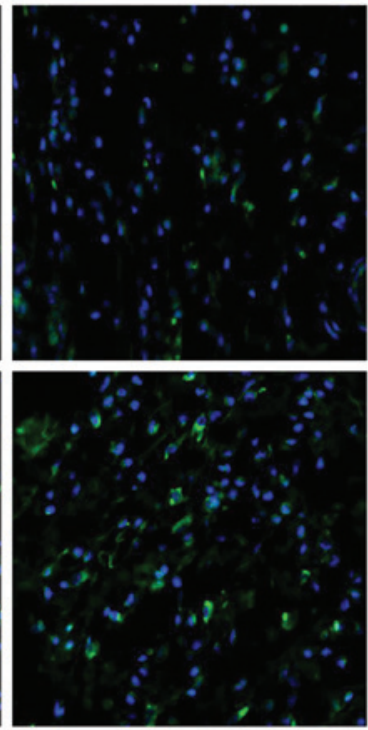

Figure 4. Effects of 4-PBA on the protein expression of CHOP and GRP78 in rat skin flaps following ischemia-reperfusion. CHOP and GRP78 protein expression levels were detected in the skin flap tissue samples (A) 6 and $24 \mathrm{~h}$ following ischemia-reperfusion by western blotting, and (B) $24 \mathrm{~h}$ following ischemia-reperfusion by immunofluorescence staining. Error bars represent the mean \pm standard deviation from five rats/group. ${ }^{*} \mathrm{P}<0.05$, vs. the control group; ${ }^{\#} \mathrm{P}<0.05$, vs. the rats treated with saline (NC). Green, CHOP and GRP78 staining; blue, nuclei staining with 4',6-diamidino-2-phenylindole. NC, negative control; 4-PBA, 4-phenylbutyrate; CHOP, CCAAT/enhancer-binding protein-homologous protein; GRP78, glucose-regulated protein 78; GAPDH, glyceraldehyde 3-phosphate dehydrogenase. 
at the convergence of the endoplasmic reticulum-to-nucleus signaling 1, protein kinase RNA-like endoplasmic reticulum kinase and activating transcription factor-6 signaling pathways (30-33). In the early stages of ER stress, GRP78 expression is upregulated, and in prolonged ER stress overexpression of CHOP is observed. In the present study, the mRNA and protein expression levels of CHOP and GRP78 were significantly increased in a time-dependent manner $6 \mathrm{~h}$ following ischemia-reperfusion injury in the skin flap tissue samples of the rats. These findings suggested that CHOP and GRP78 are two important targets for therapeutic intervention, which may allow the inhibition of ischemia-reperfusion injury progression in the skin flap of rats.

Previous studies have suggested that 4-PBA is implicated in the inhibition of ER stress-mediated ischemic injury via the transcriptional regulation of CHOP and GRP78 $(27,33,34)$. Concordant with these observations, the results of the present study demonstrated that pretreatment with 4-PBA significantly reduced the upregulation of CHOP and GRP78 in the skin flaps of the rats following ischemia-reperfusion. These alterations in CHOP and GRP78 expression levels were further supported by immunofluorescence staining. These results suggested that ER stress is important for the induction and maintenance of ischemia-reperfusion injury, and 4-PBA attenuates ER stress in this pathological condition.

In conclusion, the results of the present study suggested that 4-PBA protects against skin flap ischemia-reperfusion injury, and the mechanism underlying this process involves the inhibition of ER stress-mediated apoptosis and expression of ER stress markers, CHOP and GRP78. In addition, the study presented evidence that targeting the ER may provide a therapeutic approach for blocking the apoptotic process induced by skin flap ischemia. Finally, we proposed that the therapeutic potential of 4-PBA may extend to other ER stress-associated diseases.

\section{Acknowledgements}

The present study was supported by the Scientific Research Project of the Hangzhou Department of Technology (grant no. 20130733Q44).

\section{References}

1. Yao ST: Vascular implantation into skin flap: Experimental study and clinical application: A Preliminary report. Plast Reconstr Surg 68: 404-409, 1981.

2. Manson PN, Anthenelli RM, Im MJ, Bulkley GB and Hoopes JE: The role of oxygen-free radicals in ischemic tissue injury in island skin flaps. Ann Surg 198: 87-90, 1983.

3. Ron D and Walter P: Signal integration in the endoplasmic reticulum unfolded protein response. Nat Rev Mol Cell Biol 8: 519-529, 2007.

4. Hosoi T and Ozawa K: Endoplasmic reticulum stress in disease: Mechanisms and therapeutic opportunities. Clin Sci (Lond) 118: 19-29, 2009.

5. Hotamisligil GS: Endoplasmic reticulum stress and the inflammatory basis of metabolic disease. Cell 140: 900-917, 2010.

6. Zhang K and Kaufman RJ: From endoplasmic-reticulum stress to the inflammatory response. Nature 454: 455-462, 2008

7. Anelli $\mathrm{T}$ and Sitia R: Protein quality control in the early secretory pathway. EMBO J 27: 315-327, 2008.
8. Kim I, Shu CW, Xu W, Shiau CW, Grant D, Vasile S, Cosford ND and Reed JC: Chemical biology investigation of cell death pathways activated by endoplasmic reticulum stress reveals cytoprotective modulators of ASK1. J Biol Chem 284: 1593-1603, 2009.

9. Endo M, Mori M, Akira S and Gotoh T: C/EBP homologous protein (CHOP) is crucial for the induction of caspase-11 and the pathogenesis of lipopolysaccharide-induced inflammation. J Immunol 176: 6245-6253, 2006.

10. Li J, Wang JJ, Yu Q, Wang M and Zhang SX: Endoplasmic reticulum stress is implicated in retinal inflammation and diabetic retinopathy. FEBS Lett 583: 1521-1527, 2009.

11. Leem $\mathrm{J}$ and Koh EH: Interaction between mitochondria and the endoplasmic reticulum: Implications for the pathogenesis of type 2 diabetes mellitus. Exp Diabetes Res 2012: 242984, 2012.

12. Kang HL, Benzer S and Min KT: Life extension in Drosophila by feeding a drug. Proc Natl Acad Sci USA 99: 838-843, 2002.

13. Andreassi C, Angelozzi C, Tiziano FD, Vitali T, De Vincenzi E, Boninsegna A, Villanova M, Bertini E, Pini A, Neri G and Brahe C: Phenylbutyrate increases SMN expression in vitro: Relevance for treatment of spinal muscular atrophy. Eur J Hum Genet 12: 59-65, 2004.

14. Dasgupta S, Zhou Y, Jana M, Banik NL and Pahan K: Sodium phenylacetate inhibits adoptive transfer of experimental allergic encephalomyelitis in SJL/J mice at multiple steps. J Immunol 170: 3874-3882, 2003.

15. Burrows JA, Willis LK and Perlmutter DH: Chemical chaperones mediate increased secretion of mutant alphal-antitrypsin (alpha1-AT) Z: A potential pharmacological strategy for prevention of liver injury and emphysema in alpha 1-AT deficiency. Proc Natl Acad Sci USA 97: 1796-1801, 2000.

16. Rubenstein RC and Zeitlin PL: Sodium 4-phenylbutyrate downregulates Hsc70: Implications for intracellular trafficking of DeltaF508-CFTR. Am J Physiol Cell Physiol 278: C259-C267, 2000.

17. Perlmutter DH: Chemical chaperones: A pharmacological strategy for disorders of protein folding and trafficking. Pediatr Res 52: 832-836, 2002.

18. Yam GH, Gaplovska-Kysela K, Zuber C and Roth J: Sodium 4-phenylbutyrate acts as a chemical chaperone on misfolded myocilin to rescue cells from endoplasmic reticulum stress and apoptosis. Invest Ophthalmol Vis Sci 48: 1683-1690, 2007.

19. Shimamatsu K and Wanless IR: Role of ischemia in causing apoptosis, atrophy, and nodular hyperplasia in human liver. Hepatology 26: 343-350, 1997.

20. Kabeer FA, Sreedevi GB, Nair MS, Rajalekshmi DS, Gopalakrishnan LP, Kunjuraman $\mathrm{S}$ and Prathapan R: Antineoplastic effects of deoxyelephantopin, a sesquiterpene lactone from Elephantopus scaber, on lung adenocarcinoma (A549) cells. J Integr Med 11: 269-277, 2013.

21. Payton JE, Grieselhuber NR, Chang LW, Murakami M, Geiss GK, Link DC, Nagarajan R, Watson MA and Ley TJ: High throughput digital quantification of mRNA abundance in primary human acute myeloid leukemia samples. J Clin Invest 119: 1714-1726, 2009.

22. Hosoi T, Okuma Y and Nomura Y: Expression of leptin receptors and induction of IL-1beta transcript in glial cells. Biochem Biophys Res Commun 273: 312-315, 2000.

23. Kerrigan CL and Stotland MA: Ischemia reperfusion injury: A review. Microsurgery 14: 165-175, 1993.

24. Hatoko M, Tanaka A, Kuwahara M, Yurugi S, Iioka H and Niitsuma K: Difference of molecular response to ischemia-reperfusion of rat skeletal muscle as a function of ischemic time: Study of the expression of $\mathrm{p} 53, \mathrm{p} 21$ (WAF-1), Bax protein, and apoptosis. Ann Plast Surg 48: 68-74, 2002.

25. Kuo YR, Jeng SF, Wang FS, Huang HC, Wei FC and Yang KD: Platelet glycoprotein IIb/IIIa receptor antagonist (abciximab) inhibited platelet activation and promoted skin flap survival after ischemia/reperfusion injury. J Surg Res 107: 50-55, 2002.

26. Siemionow M and Arslan E: Ischemia/reperfusion injury: A review in relation to free tissue transfers. Microsurgery 24: 468-475, 2004

27. Qi X, Hosoi T, Okuma Y, Kaneko M and Nomura Y: Sodium 4-phenylbutyrate protects against cerebral ischemic injury. Mol Pharmacol 66: 899-908, 2004.

28. Mizukami T, Orihashi K, Herlambang B, Takahashi S, Hamaishi M, Okada K and Sueda T: Sodium 4-phenylbutyrate protects against spinal cord ischemia by inhibition of endoplasmic reticulum stress. J Vasc Surg 52: 1580-1586, 2010. 
29. Ono Y, Shimazawa M, Ishisaka M, Oyagi A, Tsuruma K and Hara H: Imipramine protects mouse hippocampus against tunicamycin-induced cell death. Eur J Pharmacol 696: 83-88, 2012.

30. Nakayama Y, Endo M, Tsukano H, Mori M, Oike Y and Gotoh T: Molecular mechanisms of the LPS-induced non-apoptotic ER stress-CHOP pathway. J Biochem 147: 471-483, 2010.

31. Vilatoba M, Eckstein C, Bilbao G, Smyth CA, Jenkins S, Thompson JA, Eckhoff DE and Contreras JL: Sodium 4-phenylbutyrate protects against liver ischemia reperfusion injury by inhibition of endoplasmic reticulum-stress mediated apoptosis. Surgery 138: 342-351, 2005.
32. Kim HJ, Jeong JS, Kim SR, Park SY, Chae HJ and Lee YC: Inhibition of endoplasmic reticulum stress alleviates lipopolysaccharide-induced lung inflammation through modulation of NF- $\mathrm{B} / \mathrm{HIF}-1 \alpha$ signaling pathway. Sci Rep 3: 1142, 2013.

33. Wang XB, Huang XM, Ochs T, Li XY, Jin HF, Tang CS and Du JB: Effect of sulfur dioxide preconditioning on rat myocardial ischemia/reperfusion injury by inducing endoplasmic reticulum stress. Basic Res Cardiol 106: 865-878, 2011.

34. Peralta $C$ and Brenner C: Endoplasmic reticulum stress inhibition enhances liver tolerance to ischemia/reperfusion. Curr Med Chem 18: 2016-2024, 2011. 